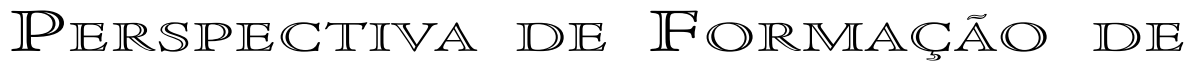

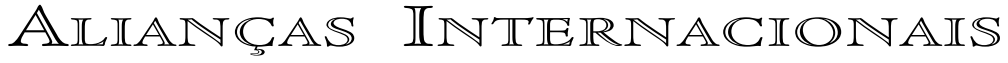

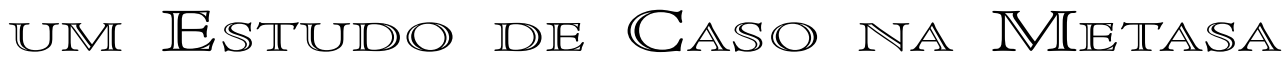 \\ Fernando Dias Lopes* \\ Fernanda Susin**
}

RESUMIO

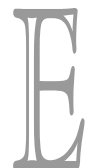

ste artigo resultou de uma pesquisa em uma empresa do setor metal mecânico de Passo Fundo/RS. A questão central foi investigar a pertinência de formação de uma aliança internacional por parte da empresa, considerando seu perfil de atuação no mercado, o seu contexto institucional de referência e a congruência dos seus objetivos com esse tipo de estratégia. Os objetivos específicos foram analisar o perfil da empresa, caracterizar o contexto institucional e estabelecer uma relação entre contexto, perfil institucional e política de alianças. O arcabouço teórico buscou conciliar visões sub e sobre socializadas (Granovetter, 1985; Roberts; Greenwood, 1997); enfatizando tanto explicações econômicas como também abordagens institucionais que explicam a formação da estratégia a partir de pressões normativas, cognitivas e coercitivas (DiMaggio; Powell, 1991; Haunschild, 1993). Observou-se na pesquisa que fatores econômicos, sociais e políticos podem interagir na determinação das escolhas da formação, ou da não formação, de estratégias.

ABSTRACT

his article resulted of an empirical research, which was developed in a company that operates in the metal-mechanical sector in South of Brazil - Passo Fundo city. The central question was investigate "what is the pertinence of forming international strategic alliances by this firm, considering its style of operation in the market, its institutional context of reference and, the congruence of its objective with this kind of strategy?". The specific objectives were to analysis the firm's characteristics, to characterize the institutional context and, to establish a relationship among context, institutional characteristics and, political of alliances. The theoretical framework seeks to conciliate both subsocialized and undersocialized views (Granovetter, 1985; Roberts; Greenwood, 1997). It seeks to stress the economic motivation to form the partnership as well the institutional explanation to the formation of strategic alliances. It was employed the concepts of normative, coercive and, mimetic institutional pressures (DiMaggio; Powell, 1991; Haunschild, 1993). It was noticed that economic, social and, political issues interact for determining the managers' choices of formation of cooperative strategy.

*Prof. PPGA/UFRN

**Bolsista PIBIQ/CNPq/Universidade de Passo Fundo/UPF 


\section{INTRODUÇ $\tilde{A} O$}

literatura sobre gestão vem, desde a década de 1960, apontando as mudanças na sociedade e, mais especificamente, no ambiente organizacional, como um elemento central para compreensão das transformações na natureza e dinâmica das organizações (DRUCKER, 1995; BELL, 1973; CLEGG, 1990). Nomes diferentes e formas diferentes de interpretar essas mudanças vêm sendo construídas, dando nomes distintos ao mesmo fenômeno, como, por exemplo, a sociedade pós-capitalista de Peter Drucker, a sociedade pós-industrial de Daniel Bell, a terceira onda de Alvin Tofler e a sociedade pós-moderna de Stewart Clegg. As interpretações dessa nova sociedade, por sua vez, pautam-se em arcabouços teóricos distintos, que vão de uma abordagem funcionalista e conservadora a uma abordagem mais crítica - humanismo radical e estruturalismo radical (BURREL \& MoRGAN, 1979). Evidentemente que essas transformações permitem diferentes leituras, suscitadas pela natureza multifacetada dos fenômenos sociais (Morgan, 1996). As transformações de uma sociedade industrial para uma sociedade pós-industrial, ou de uma sociedade moderna para uma sociedade pós-moderna ( $\mathrm{H}_{\mathrm{ATCH}}$ 1997), produziram várias implicações nos processos e estruturas organizacionais (Quadro 1). Tais transformações, por sua vez, trouxeram implicações na formação de novas estratégias de sobrevivência organizacional. Entre essas novas estratégias estão as alianças internacionais, as quais operam em sintonia com as necessidades de inovação, internacionalização, flexibilização e diversidade cultural.

Quadro 1- Comparação das Características Associadas ao Industrialismo e ao Pós-Industrialismo

\begin{tabular}{|l|l|l|}
\hline VARIÁVEIS & INDUSTRIALISMO & Pós-INDUSTRIALISMO \\
\hline AMBIENTE & $\begin{array}{l}\text { Estado-nação regula } \\
\text { economias nacionais; } \\
\text { Marketing de massa; } \\
\text { Padronização; } \\
\text { O estado de bem estar } \\
\text { social }\end{array}$ & $\begin{array}{l}\text { Competição global; } \\
\text { Desconcentração do capital com } \\
\text { relação ao estado-nação; } \\
\text { Fragmentação dos mercados e } \\
\text { descentralização internacional da } \\
\text { produção; } \\
\text { Aumento da escolha do consumidor e } \\
\text { demanda por produtos customizados; } \\
\text { Crescimento dos movimentos sociais }\end{array}$ \\
\hline TECNOLOGIA & $\begin{array}{l}\text { Produção em massa ao } \\
\text { longo da linha } \\
\text { taylorista/fordista; } \\
\text { Rotina; } \\
\text { Manufacturing output }\end{array}$ & $\begin{array}{l}\text { Manufatura flexível e automação; } \\
\text { Uso do computador para design, } \\
\text { produção e controle de estoque; } \\
\text { Sistemas just-in-time (JIT); } \\
\text { Ênfase sobre velocidade e inovação; } \\
\text { Service/information output }\end{array}$ \\
\hline $\begin{array}{l}\text { ESTRUTURA } \\
\text { SOCIAL }\end{array}$ & $\begin{array}{l}\text { Burocrática; } \\
\text { Hierarquia com ênfase } \\
\text { na comunicação vertical; } \\
\text { Especialização; } \\
\text { Integração horizontal e } \\
\text { vertical; } \\
\text { Focada no controle }\end{array}$ & $\begin{array}{l}\text { Novas formas organizacionais (redes, } \\
\text { alianças estratégicas, organização } \\
\text { virtual); } \\
\text { Hierarquias achatadas com } \\
\text { comunicação horizontal e } \\
\text { responsabilidade gerencial devolvida; } \\
\text { Outsourcing; } \\
\text { Mecanismos informais de influência } \\
\text { (participação, cultura, comunicação); } \\
\text { Desintegração horizontal e vertical; } \\
\text { Fronteiras frouxas entre funções, } \\
\text { unidades e organizações }\end{array}$ \\
& \begin{tabular}{l}
$\mid l$ \\
\hline
\end{tabular} &
\end{tabular}




\begin{tabular}{|l|l|l|}
\hline CULTURA & $\begin{array}{l}\text { Celebra a estabilidade, } \\
\text { tradição, costumes; } \\
\text { Valores organizacionais: } \\
\text { crescimento, eficiência, } \\
\text { padronização e controle }\end{array}$ & $\begin{array}{l}\text { Celebra incerteza, paradoxo e a moda; } \\
\text { Valores organizacionais: qualidade, } \\
\text { serviços ao consumidor, diversidade e } \\
\text { inovação }\end{array}$ \\
\hline $\begin{array}{l}\text { ESTRUTURA } \\
\text { FÍSICA } \\
\text { (tempo- } \\
\text { espaço) }\end{array}$ & $\begin{array}{l}\text { Concentração das } \\
\text { pessoas em centros e } \\
\text { cidades industriais; } \\
\text { Orientação local e } \\
\text { nacionalista; } \\
\text { Tempo é linear }\end{array}$ & $\begin{array}{l}\text { Desconcentração das pessoas; } \\
\text { Redução no tempo de transporte liga } \\
\text { espaços distantes e encoraja } \\
\text { orientação global e internacional; } \\
\text { Compressão da dimensão temporal } \\
\text { (encurtamento do ciclo de vida dos } \\
\text { produtos) leva a simultaneidade }\end{array}$ \\
\hline $\begin{array}{l}\text { NATUREZA } \\
\text { DO }\end{array}$ & $\begin{array}{l}\text { Rotina; } \\
\text { Trabalho desqualificado; } \\
\text { TRABALHO }\end{array}$ & $\begin{array}{l}\text { Complexo frenético; } \\
\text { Eabilidades baseadas no } \\
\text { conhecimento; } \\
\text { das tarefas } \\
\text { Times de trabalho multi funcionais; } \\
\text { Grande ênfase sobre aprendizagem; } \\
\text { Mais outsourcing, subcontratação, } \\
\text { empregabilidade e teletrabalho }\end{array}$ \\
\hline
\end{tabular}

Fonte: Hatch (1997, p. 26)

O Brasil na década de 90 entrou em um ritmo mais acelerado de transformação, flexibilizando as fronteiras de seu mercado e criando um ambiente mais exigente em termos de tecnologia, inovação e qualidade. Setores como cosméticos, calçados e brinquedos, por exemplo, passaram a ser pressionados a adotar novas estratégias para responder aos concorrentes internacionais e assegurar não somente a participação conquistada no mercado internacional, como também se manter competitivos no mercado interno. Considerando que o setor metal mecânico também vem passando por transformações, decorrentes de um novo ambiente institucional, este artigo apresenta como questão central verificar qual a pertinência de formação de alianças internacionais por parte de uma empresa de Passo Fundo/RS, considerando seu perfil de atuação no mercado, o seu contexto institucional de referência e a congruência dos objetivos da empresa com esse tipo de estratégia. O artigo também busca, de forma exploratória, identificar os benefícios que arranjos cooperativos podem produzir para a organização pesquisada, bem como as limitações que enfrentará para formar tais arranjos.

O trabalho é resultado de um estudo puramente qualitativo, centrado no método de estudo de caso. Os dados foram obtidos através de consulta a documentos da empresa, reportagens sobre o setor e relatórios de consultores que atuam junto às empresas do setor metal mecânico da região de Passo Fundo/RS. Também foram coletados dados primários através de entrevista em profundidade com um dos diretores da empresa. A entrevista teve duração de 60 minutos e foi transcrita literalmente para posterior análise de conteúdo.

\section{ALIANCGAS ESTRATÉGICAS INTEIRNACIONAIS -

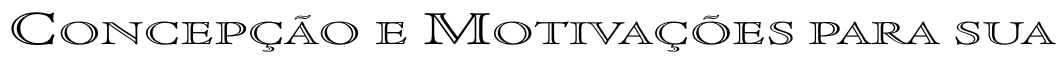 FORMAÇÃO}

A década de 1970 foi marcada pelo domínio das estratégias competitivas, podendo-se destacar os trabalhos produzidos por Michael Porter. A escola do posicionamento (Mintzberg et al., 2000) trouxe para o estudo da estratégia uma preocupação maior com o conteúdo da estratégia, assumindo a existência de um conjunto limitado de estratégias genéricas de sobrevivência. 
As estratégicas de cooperação, ainda que não sejam novidades no mundo dos negócios, se tornaram mais evidentes na década de 1990. Oliveira et al. (1999, p.100) citam como razões desse crescimento:

a) a dificuldade de as empresas individualmente manterem-se competitivas em ambientes cada vez mais complexos, caracterizados por rápidas e contínuas transformações tecnológicas;

b) a revolução tecnológica no setor de telecomunicações e a queda nos custos de transporte;

c) a formação de blocos econômicos, como Nafta, UE e Mercosul, que procuram, por meio da união das potencialidades das empresas dos países componentes, manter-se competitivos perante os demais;

d) o desejo de países de economias emergentes de atrair investimentos externos, o que tem resultado na liberalização de legislações nacionais em relação à entrada de tais investimentos.

Cooperação pode ser operacionalizada através de estratégias pontuais ou através de arranjos estruturais construídos em níveis distintos de complexidade. A literatura tem definido esses arranjos dentro do conceito de networks ou alianças (Bleek \& Ernst, 1993; Alter \& Hage, 1993). As networks, por sua vez, englobam as alianças estratégicas, as joint ventures, os acordos de cooperação tecnológica, fusões, entre outros. Diante da diferenciação desses arranjos organizacionais em relação às duas formas clássicas de coordenação - mercados e hierarquias - surgiu na literatura um debate que procura defini-las ou como novas formas (Powell, 1990; Borys \& Jeminson, 1989) ou como uma forma híbrida (Williamson, 1985; Thorelli, 1986; Powell, 1987).

Network como uma forma híbrida é assim assumida pela incorporação de elementos de mercado e hierarquia ao mesmo tempo. Williamson (1996) salienta que determinadas transações podem apresentar determinado grau de especificidade e recorrência, exigindo ativos específicos, mas que não comportam os custos de uma hierarquia e, ao mesmo tempo, não podem ser conduzidas livremente no mercado. Nesse sentido, opta-se por uma forma híbrida capaz de manter os custos de transação em níveis que garantam a eficiência da organização.

Powell (1990), por sua vez, defendeu que networks são novas formas que apresentam características distintas de mercados e hierarquias, não podendo ser caracterizadas simplesmente como formas híbridas. Baseado em estudos empíricos realizados em diferentes setores e por diferentes autores, Powell (1990) identificou as seguintes características para esses arranjos:

1) Bases normativas: complementaridade de forças;

2) Meios de comunicação: relacional;

3) Métodos de resolução de conflitos: normas de reciprocidade - preocupação reputacional;

4) Grau de flexibilidade: médio;

5) Montante de comprometimento entre as partes: médio para alto;

6) Tom ou clima: open-ended, benefícios mútuos;

7) Preferência e escolha de atores: independente;

8) Mistura de formas: status hierárquico, múltiplos padrões e regras formais.

Baldi e Lopes (2002) assumem uma terceira posição ao salientarem que networks podem resultar em uma grande variedade de formas, tão heterogêneas que dificilmente se encaixam em uma única categoria de estrutura de governança. Lopes (2003), em estudo realizado em uma joint venture sediada no Brasil, identificou nela um conjunto de características que a aproximam de uma hierarquia, embora ela mantenha elementos de mercado e elementos distintos de mercado e hierarquia ao mesmo tempo. No entanto, ao analisar um consórcio formado entre universidades comunitárias no Rio Grande do Sul, identificou as características diferencias apresentadas por Powell (1990), que caracterizam networks como uma nova forma organizacional. 
A variedade de formas assumidas pelas networks e alianças internacionais também é acompanhada de uma variedade de motivos para sua formação. Para explicar as motivações, é possível recorrer a diferentes abordagens teóricas como a Economia dos Custos de Transação, a Teoria da Dependência de Recursos, a Teoria Institucional, entre outras.

Rodrigues (1999) identificou que muitas empresas multinacionais, investindo no Brasil, têm buscado acesso ao mercado nacional e ao Mercosul. Outras têm usado suas instalações industriais no Brasil como uma base para exportar. Por outro lado, Vasconcelos e Henrique (apud RodRIGUEs, 1999) pesquisaram 33 joint ventures no Brasil e descobriram que empresas nacionais têm como seus principais objetivos obter tecnologia, ganhar vantagens competitivas contra competidores locais e explorar vantagens associadas com propriedade tecnológica que obtêm através de licença e controle na economia doméstica, ou através do acesso às patentes estrangeiras, além do poder obtido pelo acesso aos mercados internacionais.

Pfeffer e Nowak (1972) apresentam alianças como uma ferramenta para gerenciar interdependências organizacionais, sejam elas competitivas ou simbióticas. Salientam, ainda, que arranjos interorganizacionais são importantes como mecanismos para distribuir os riscos de novos investimentos industriais; estabelecer serviços conjuntos ou combinados para obter maior economia ao acumular o grande montante de capital requerido; e viabilizar programas que dificilmente estariam ao alcance de companhias operando individualmente.

Partindo da abordagem de Economia dos Custos de Transação, Contractor e Lorange (1988) também identificaram um conjunto de objetivos que poderiam guiar a formação de vários tipos de arranjos cooperativos, a saber:

a) reduzir risco;

b) racionalizar e alcançar economia de escala;

c) intercambiar tecnologia;

d) cooptar ou bloquear competição;

e) superar barreiras governamentais;

f) facilitar expansão internacional inicial de firmas inexperientes;

g) alcançar as vantagens de quase integração vertical através do vínculo de contribuições complementares dos parceiros em uma cadeia de valor.

Oliver (1990) adota uma perspectiva integrativa para explicar a formação de relacionamentos interorganizacionais. Ao fazer referência a Economia dos Custos de Transação (ECT), Teoria da Dependência de Recursos (DR), Teoria Institucional (TI), teoria da troca, entre outras, a autora identificou seis determinantes gerais da formação de relacionamentos cooperativos:

- Necessidade: organizações desenvolvem AEs para atender às necessidades legais ou a requerimentos regulatórios;

- Assimetria: para a autora tanto o desejo por controle, quanto à relutância de ser controlado reflete um motivo assimétrico para formar alianças estratégicas (AEs);

- Reciprocidade: este motivo contrasta com assimetria ao enfatizar que relacionamentos cooperativos interorganizacionais estão baseados em cooperação, colaboração e coordenação ao invés de dominação, poder e controle;

- Eficiência: relacionamentos interorganizacionais podem ser empregados por organizações como mecanismos para aumentar suas taxas internas de input e output;

- Estabilidade: relacionamentos interorganizacionais podem ser empregados como um mecanismo para adaptabilidade à instabilidade ambiental;

- Legitimidade: relacionamentos interorganizacionais são importantes porque possibilitam às organizações ganhar ou aumentar reputação, imagem, prestígio, ou para alcançar congruência com normas prevalecentes em seus ambientes institucionais.

Outros autores como Powell (1990, 1998); Gulati (1998); Larson (1992), entre outros têm empregado abordagens sócio-culturais para explicar a formação de alianças estratégicas. Tais autores dão ênfase ao contexto institucional, salien- 
tando a capacidade do ambiente sócio-cultural em moldar a estrutura e o padrão de decisão dos dirigentes. As relações sociais são apontadas por esses autores como referenciais para a escolha de parceiros, para a decisão da estrutura de cooperação e sobre a perspectiva de longevidade da parceria. Para justificar a importância do contexto sócio cultural, Powell (1990) destaca:

- $\quad$ economias estão imersas em forças sociais e culturais. Assim, mercados são vistos como sendo "estruturados por um complexo de fatores locais, éticos, culturais de comércio e por regimes variados de regulação do estado" (Powell, 1990, p.229);

- $\quad$ o mercado não é uma instituição natural autoperpetuante, mas uma construção social e cultural;

- $\quad$ mercados não podem ser isolados da estrutura social, uma vez que acesso social diferenciado resulta em assimetrias em informações, bem como estrangulamentos, provendo, assim, para algumas partes, consideráveis benefícios e deixando outras em desvantagem.

Finalmente, pode-se argumentar que embora alianças estratégicas sejam fenômenos econômicos em si, aspectos sociais devem ser levados em consideração na análise de sua formação. Ao se considerar que a economia é imersa nas relações sociais (Granovetter, 1985) e que o ambiente institucional influencia em graus diferenciados todas as organizações (DiMaggio \& Powell, 1991), torna-se fundamental dar especial atenção aos fatores sócio-culturais em conjunto com os fatores econômicos. Enquanto Granovetter (1985) salienta a importância dos laços sociais como orientadores da ação econômica (por exemplo, a escolha de um parceiro), DiMaggio e Powell (1991) vão salientar o papel do estado, das profissões e dos valores legitimados pela sociedade como determinantes da ação e estrutura da organização. Assim, para análise do caso, os autores consideraram os aspectos internos que explicam e justificam a formação de parceria como também as características do ambiente e do setor em que a mesma está inserida. Em outras palavras, são considerados para análise teorias que partem de níveis distintos de análise (individual e inter-organizacional).

Os estudos sobre gestão internacional ainda são incipientes no Brasil, mas têm ganhado destaque nos últimos anos. Assim, além dos estudos já citados de Oliveira et al.(1999), Rodrigues (1999) e Lopes (2003), outros estudos empíricos realizados por autores brasileiros têm produzido contribuições significativas para compreender tal fenômeno no ambiente local. Entre esses, pode-se citar o trabaIho de Balestro et al. (2004, p. 181), os quais, a partir de um estudo da Rede PETRO-RS, descrita pelos autores como experiência pioneira de uma rede de empresas fornecedoras da cadeia de suprimentos da indústria de petróleo e gás, sustentam que "(...) a organização em torno de uma rede voltada para o mercado e o desenvolvimento tecnológico contribui para os recursos das organizações, subsidiando o desenvolvimento das capacidades dinâmicas" .

Já Cyrino e Júnior (2002) conduziram uma pesquisa, ao longo de 2001, que objetivou um melhor entendimento do contexto e das estratégias adotadas pelas empresas brasileiras que estão internacionalizando suas operações e as razões porque muitas empresas brasileiras não consideram essa possibilidade. Verificaram que as grandes empresas brasileiras ainda estão em estágio inicial nos seus processos de internacionalização e têm adotado uma postura gradualista a respeito desses processos. Também identificaram que empresários brasileiros têm atribuído ao chamado "custo Brasil" o principal entrave ao processo de internacionalização.

$\mathrm{Na}$ linha deste trabalho pode-se destacar a pesquisa de Laniado e Baiardi (2003), os quais analisaram a importância da cooperação empresarial na Bahia a partir da formação de redes, indicando-as como um marco de ação coletiva. Com base na teoria da imersão social, os autores chamaram a atenção também para o fato de que a ação econômica não se reduz à ação instrumental e funcional dos agentes. Essa, constitui-se uma importante vertente teórica para o estudo de arranjos cooperativos que tem ganhado cada vez mais espaço na literatura nacional. 


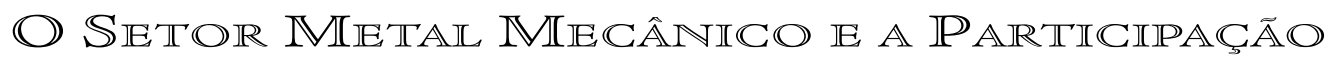

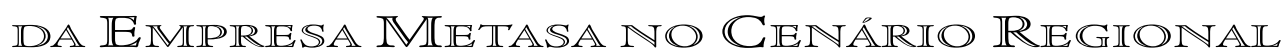

O processo de fabricação do setor metal-mecânico incorpora máquinas que substituem o trabalho humano em um amplo conjunto de operações, porém permanece a intervenção direta dos trabalhadores que realizam a integração e alimentam estas máquinas, caracterizando o processo de fabricação deste setor como descontínuo.

O setor metal-mecânico é um setor-chave para a economia da região de Passo Fundo e está inter-relacionado com as atividades de produção agrícola, tais como soja e trigo, atividade principal da região.

\section{CONTEXTUallização do Setor - Ano De 2002}

Segundo dados da Abimaq (Associação Brasileira da Indústria de Máquinas e Equipamentos), o setor metal mecânico superou as expectativas com desempenho positivo no ano de 2002, apresentando um crescimento do faturamento nominal de $13,68 \%$ em relação ao ano anterior. Deve-se a esse aumento o desempenho das exportações com um crescimento de $3 \%$, bem como o aumento no faturamento de alguns subsetores como o de máquinas e implementos agrícolas e mecânica pesada.

O setor sofreu influências da crise da Argentina, na qual reduziu suas importações em $67,79 \%$, porém, realizou grandes esforços exportadores que compensaram as perdas para o país vizinho, buscando mercados alternativos como China, Rússia, África do Sul e Índia, além da ampliação da participação nos mercados tradicionais. Estados Unidos, Alemanha e Reino Unido são os países que lideram as compras, comprovando assim a competitividade dos fabricantes brasileiros.

Anualmente, a Abimaq realiza pesquisas junto aos fabricantes de máquinas e equipamentos sobre os investimentos realizados e previstos para o setor. A pesquisa evidenciou que os investimentos obtiveram um crescimento de $80,4 \%$ quando comparado ao ano anterior, cuja maior parte desses investimentos foi destinada à ampliação da capacidade industrial e à modernização e aperfeiçoamento dos parques produtivos, no sentido de aumentar tanto a capacidade de produção quanto o desenvolvimento e aprimoramento de tecnologias. Houve um índice acentuado de treinamento da mão-de-obra, visando à melhoria da qualidade dos produtos.

A pesquisa indicou um investimento previsto de $13 \%$ acima desse balanço para o ano de 2003.

CONTEXTUALIZAÇÃO DO SETOR - ANO DE 2003

Segundo indicadores da Abimaq (Associação Brasileira da Indústria de Máquinas e Equipamentos), as indústrias de bens de capital mecânico encerraram o primeiro semestre de 2003 com crescimento significativo das exportações, devido à contração do mercado interno, com crescimento de 30,3\% (janeiro a agosto) em relação ao mesmo período do ano anterior.

Esse aumento nas exportações deu-se após a desvalorização cambial de 1999 (ano em que ocorreu a maxidesvalorização do real e a mudança de câmbio fixo para flutuante), em que os fabricantes desse segmento foram em busca de mercado externo e da competitividade necessária, aprimorando tecnologia e conferindo qualidade aos produtos. Esta iniciativa contribuiu para a relevância conquistada pelo setor, que é o segundo maior exportador industrial brasileiro. 
Os principais destinos das máquinas e equipamentos brasileiros, segundo a Abimaq, foram: Estados Unidos (US\$ 949,76 milhões), Argentina (US\$242,19 miIhões), Alemanha (US\$237,07 milhões), México (US\$193,51 milhões), Reino Unido (US\$184,71 milhões) e China (US\$130,84 milhões).

As importações de máquinas caíram $14,9 \%$, em relação ao ano anterior, indicando uma participação da indústria local no mercado de consumo e reduzindo, assim, pela primeira vez, o déficit da balança comercial, refletindo uma queda de $67,22 \%$ e gerando uma economia de $\mathrm{R} \$ 4,2$ bilhões para o país. Esses dados demonstram que continua em curso um processo de substituição competitiva de importações no setor, independente da valorização do real frente ao dólar. Além disso, demonstram um avanço tecnológico frente aos produtos similares importados.

O faturamento nominal do setor apresentou crescimento de $8 \%$, contribuindo, para isso, o bom desempenho das vendas externas e de alguns subsetores como os de máquinas e implementos agrícolas e máquinas-ferramenta.

Apesar de ainda apresentar resultados positivos, assegurados pelas exportações e referentes ao primeiro quadrimestre de 2003 (resultados previstos, segundo o presidente da Abimaq, Luiz Carlos Delben Leite), o setor mostra um desaquecimento no faturamento, isto, devido aos reflexos da redução das encomendas verificadas com maior ênfase no segundo semestre de 2002. Segundo o presidente da Abimaq, essas quedas irão amenizar-se com as perspectivas de melhoras no comportamento econômico, tais como as quedas das taxas de juros e a aprovação da Reforma Tributária, as quais passarão a influenciar como indutores de maior confiança por parte dos investidores.

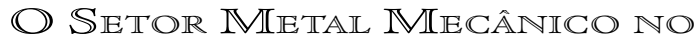
ESTADO IDO RIO GRANDE DO SUL

A colonização italiana, que se instalou na Serra, trouxe indústrias de alimentação, principalmente as vinícolas, mais os setores de metalurgia e mecânica, tendo neste último, hoje, um dos seus pontos mais fortes na participação da economia.

Segundo dados da FIERGS (Federação e Centro das Indústrias do Estado do Rio Grande do Sul), o pólo metal mecânico do RS já é o maior do continente na produção de ônibus, implementos rodoviários (reboques e semi-reboques) e caminhões fora-de-estrada, tendo um significativo crescimento com a implantação da fábrica da GM em Gravataí.

Uma importante característica do perfil econômico-financeiro do Estado é a produção voltada para a exportação, sendo Estados Unidos, Argentina, Alemanha e Reino Unido os países que mais importam produtos como calçados, fumo, máquinas, carnes e soja do Estado.

Caxias do Sul configura-se como o segundo maior pólo brasileiro do setor metal-mecânico, perdendo apenas para São Paulo. Esse setor assegura para os cofres estaduais 3\% do volume total de seu Produto Interno Bruto. Com mais de 1,2 mil indústrias ligadas ao setor metal-mecânico, Caxias do Sul é considerada um pólo de especialização na área de peças automotivas, contando com dois centros tecnológicos para a formação de técnicos e desenvolvimento de tecnologia.

Como 30 pólo do setor, Panambi, desde 1914, se tornou conhecida como a cidade das máquinas pelo crescimento de seu parque industrial. O crescimento da indústria, muito se deve à estrutura do sistema educacional que disponibiliza centros de formação através de cursos profissionalizantes nas áreas técnicas industriais e um curso de extensão da Universidade de Unijuí, que oferece anualmente 100 vagas gratuitas para os cursos de engenharia mecânica. Este incentivo faz surgir, todos os anos, novas empresas formadas pelos próprios alunos destas escolas. 


\section{O Setor Mietal Miecânico na Ciddade de Passo Fundo}

Segundo Corrêa (2003), o arranjo produtivo do setor metal mecânico está localizado na Região da Produção do Estado do Rio Grande do Sul, e como cidades-pólo destacam-se Passo Fundo e Marau. Nos setores de implementos agrícolas, metalurgia e plásticos, os integrantes da cadeia vão desde a fabricação da matéria-prima e outros insumos até o produto final, destacando-se como principais atividades a produção de máquinas e implementos agrícolas, peças injetadas em $\mathrm{PP}$ e $\mathrm{PE}$, fibra de vidro e a produção de estruturas metálicas.

A primeira empresa do setor na cidade de Passo Fundo, segundo Hexsel e Gárate (2002), foi representada pela filial Fábrica de Pregos "Hugo Gerdau" S/A, instalada em 1933, permanecendo com suas atividades até 1962 quando foi transferida para Sapucaia do Sul por necessidade de expansão.

O setor metal mecânico vem ocupando o $4^{\circ}$ lugar na participação do valor adicionado do município desde o ano de 2002.

As empresas do arranjo são responsáveis por suprir o mercado nacional e internacional, destacando-se as empresas Metasa, Semeato, Bandeirante e Marini, sendo que as demais atuam no mercado local e regional. (CORRÊA, 2003).

Na região existem representantes de máquinas e equipamentos comerciais para o setor Metal Mecânico, não existindo nenhuma empresa que as produza no município ou região. Como fornecedoras de insumos, encontram-se empresas de Passo Fundo, Caxias do Sul e a Grande Porto Alegre.

Das instituições locais voltadas para a formação de profissionais para a área, destaca-se a Universidade de Passo Fundo, colégios técnicos, Senai e Senac.

Entre os fatores críticos no setor, evidenciados na pesquisa de Corrêa (2003), destacam-se as poucas interações entre empresas do mesmo arranjo, ou outros arranjos, com empresas de outras regiões do estado. A falta de informações sobre o mercado, tanto interno como externo, bem como a falta de articulação entre as grandes e pequenas empresas fazem com que muitos produtos que poderiam ser desenvolvidos e produzidos no município por empresas locais sejam buscados em outros mercados. Não há um sistema de logística na região, fazendo com que os custos de movimentação dos produtos e insumos sejam altos. Há muita burocracia para o acesso a crédito financeiro. Não existe entre os empresários uma consciência empreendedora quando o assunto é a articulação para buscar novas tecnologias. A mão-de-obra é pouco qualificada e há pouca interação entre as empresas e entre as empresas e as instituições de ensino. As empresas âncoras sentem dificuldade em buscar e exigir a capacitação dos seus fornecedores de menor porte de Passo Fundo, tanto pela falta de interesse como pelo baixo grau de escolaridade. Existe alta competitividade entre as empresas, impedindo o fortalecimento do grupo. Um fator limitante para a ampliação do parque fabril das empresas é a falta de espaço físico no município de Passo Fundo.

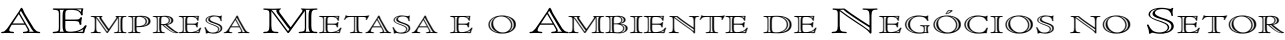
DE $\mathbb{M}$ Áquinas $\mathbb{E}$ Equipamintos Agrícollas

A Metasa foi fundada em 30 de dezembro de 1975, sob a denominação Metalúrgica Arco Vila S/A, em Marau. As atividades industriais começaram em setembro de 1976, produzindo esquadrias metálicas em uma área coberta de $1.800 \mathrm{~m} 2$, com 16 funcionários. Em 1979 iniciaram as primeiras atividades na produção de estruturas metálicas.

Em 1981, foi inaugurado, em Porto Alegre, o escritório comercial, com o objetivo de expandir as vendas, bem como divulgar a Metasa no mercado nacional. Em 1982, foi alterada a Razão Social, surgindo então a Metasa S.A - Indústria Metalúrgica. Hoje, com 300 empregados e um parque fabril de $16.000 \mathrm{~m} 2$ de área 
construída em Marau, a Metasa projeta, desenvolve, fabrica e comercializa estruturas metálicas.

Em julho de 1997, a empresa instalou em Passo Fundo uma filial com $12.000 \mathrm{~m} 2$ de área construída, para a produção de máquinas e implementos agrícolas, setor dominado por empresas nacionais. Hoje, a Divisão Agrícola Metasa, como é chamada, está instalada em uma área de $120.000 \mathrm{~m}^{2}$. Tem de área construída $15.300 \mathrm{m2}$, distribuídos da seguinte forma: edificação na qual funciona a área administrativa; edificação na qual estão instalados o refeitório, vestiários e o setor de RH e treinamento; pavilhão industrial destinado à fundição de peças para máquinas agrícolas; pavilhão industrial para os setores de Estamparia, Solda; pavilhão industrial para Usinagem, Matrizaria, Tratamento Térmico, Almoxarifado Central, Pintura e Montagem de Implementos Agrícolas; e um último pavilhão industrial, construído recentemente, que une os dois últimos, formando um único bloco de pavilhões industriais para um melhor fluxograma de produção.

Em 1998, recebeu o Prêmio Novidade 98 - Melhores da Terra, conferido pela Secretaria da Agricultura e Abastecimento do Estado do Rio Grande do Sul e a Gerdau. Em agosto de 1998, firmou parceria com a URSUS CONPANY, da Polônia. Foi agraciada, em 1999, com o Prêmio Distinção Indústria de Melhor Máquina para Transplantadora de Mudas - MTM 2000 pela FIERGS-CIERGS, colocando a Metasa em evidência nacional.

Sua produção concentra-se nos implementos agrícolas como máquinas para plantio. Desta forma, este trabalho, irá se concentrar na divisão de máquinas e implementos agrícolas da empresa Metasa. Diferentemente do setor de máquinas alto-propelidas (tratores e colheitadeiras), o qual é dominado por grandes companhias multinacionais - John-Deer, AGCO do Brasil, New Holland e Valmet -, o setor de máquinas e implementos agrícolas é disputado basicamente por empresas nacionais. A Metasa, com dezoito concorrentes internos, ocupa, hoje, a quarta posição nesse segmento, dominando aproximadamente $12 \%$ do mercado.

O setor de máquinas e implementos agrícolas no Brasil ainda depende de avanços tecnológicos significativos para se inserir melhor na economia internacional, ainda que as empresas brasileiras já exportem para vários mercados, principalmente América Latina.

Para o diretor da Metasa existem evidências de uma tendência de internacionalização desse setor, uma vez que empresas européias líderes estão movimentando-se para ingressar mais agressivamente em mercados de países emergentes, tais como China, Índia, México e Brasil. Segundo ele, o mercado europeu esta saturado e a exportação para mercados emergentes é prejudicada pela incapacidade dos produtores locais assumirem o preço e custo de importação de tais equipamentos. Nesse sentido, a produção precisa ser realizada com base nos custos do país consumidor do equipamento. Por outro lado, empresas locais precisam de mais tecnologia, ainda que tenham tecnologia superior e dominante na produção de equipamentos para plantio direto, que constitui um tipo específico de produto. Vale lembrar que a tecnologia de produto para plantio direto é de interesse dos fabricantes europeus, uma vez que o plantio direto tem menor impacto ambiental. As empresas européias, por sua vez, dominam tecnologias de produtos a base de laser (por exemplo, colheitadeiras com corte a laser).

Os produtores de máquinas europeus também precisam criar mecanismos para produzir com custos menores para atender ao mercado do leste europeu e parte da Ásia, o que já vem sendo feito na China por empresas alemãs e austríacas. Nesse segmento, os chineses têm oferecido aos parceiros estrangeiros oportunidades de mercado e estrutura de produção e obtido em troca conhecimento gerencial e tecnologia de produto.

Outro fator importante no atual contexto é a presença de investidores internacionais na região. Eles têm feito propostas de aquisições, visitam fábricas e acompanham o trabalho das empresas nas feiras locais, regionais e internacionais.

O Brasil é particularmente atraente para investidores internacionais nesse setor por já dispor de uma sólida estrutura de produção e, por já estar abastecen- 
do parte do mercado latino americano. Países como Peru, Equador e Chile, os quais são compradores tradicionais de fabricantes europeus de máquinas e implementos, já estão começando a se abastecer de produtos fabricados no Brasil.

Em termos de mercado, o Brasil como um grande produtor de grãos, tende a ampliar suas atividades. As projeções indicam que o Brasil vai passar de $40 \mathrm{mi}-$ Ihões de hc. de área de plantio para 90 milhões de hc., o que desperta um interesse ainda maior de empresas internacionais.

Para as empresas locais, fatores como o custo do dinheiro - taxas elevadas de juros - dificulta investimentos para acompanhar o crescimento da demanda e desenvolvimento tecnológico para ingressar em mercados com demandas mais sofisticadas.

Outro aspecto que pode ser interpretado como indicador de uma tendência ao crescimento de parcerias internacionais é a especificidade do mercado brasileiro e latino americano. Segundo o diretor da Metasa, as máquinas européias precisam sofrer adaptações significativas para o mercado brasileiro, as quais poderiam ser realizadas pelas empresas nacionais que já conhecem as especificidades do solo brasileiro decorrente de vários anos de pesquisa em parceria com universidades e outros institutos de pesquisa como a EMBRAPA.

[...] nós podemos trazer tecnologia da Europa, não muitas vezes no conjunto da máquina. Nós podemos trazer nos detalhes da máquina, em alguns conjuntos e subconjuntos, porque a máquina brasileira tem que ser uma máquina mais robusta, e não é só no Brasil, na América Latina toda. (Dir. Metasa)

Quanto à política de relação com fornecedores, a Metasa busca hoje a formação de sistemistas na região. Assim, reduziu a pulverização de fornecedores e investiu na qualificação de empresas locais, fornecendo, às vezes, até a matéria-prima.

Quanto à atuação no mercado internacional, a mesma tem ocorrido através de exportação, utilizando-se de revendedores e distribuidores. A empresa, em um segmento distinto do que objeto deste estudo, formou uma join-venture no ramo de pivot de irrigação, com uma empresa austríaca, criando a Bawer-Metasa. O controle desta aliança é dividido, ou seja, a comercialização dá-se pela Bawer, e a Metasa participa com a produção e fabricação dos equipamentos. Tal experiência avaliada como positiva, fortaleceu a tendência de formação de parcerias no setor de máquinas e implementos agrícolas.

A Metasa é uma empresa com orientação para produção, o que se explica pelo elevado controle das atividades estratégicas por engenheiros e que pode ser evidenciado pela fala do presidente apresentada a seguir:.

[...] a nossa base é a criação, nós temos um setor de engenharia que dá sustentação para que a gente se atualize, para que a gente possa participar, inovar né. Então, lógico, a engenharia dá.....é o ponto de partida para o desenvolvimento dos nossos produtos. (Dir. Metasa)

Hoje a empresa tem uma política sistemática de pesquisa e desenvolvimento. Já existem projetos financiados pela FINEP para desenvolvimento de novos produtos, além de parcerias com a EMBRAPA e universidades comunitárias e federais. Esta base de pesquisa é fundamental para a realização de intercâmbio tecnológico com parceiros internacionais. Os dirigentes vêem a inovação e os investimentos em tecnologia e treinamento como principais fatores responsáveis por um crescimento de 81,33\%, no faturamento de 2002 para 2003.

A direção da empresa é parcialmente profissionalizada, mantendo membros da família nas operações ao lado de executivos contratados. A empresa desenvolve atividades de planejamento de forma sistemática. Essa estrutura de governança, diferentemente das empresas com direção não profissionalizada, facilita o processo de negociação.

Percebe-se que a administração da empresa tem visão do mundo globalizado, que embora não veja perspectivas de formar alianças com empresas concorrentes 
nacionais, devido à cultura que essas apresentam, não possui restrições à formação dessas parcerias, no intuito de compartilhar e desenvolver tecnologia, para se obter diferencial não em função de preço, mas em produto, qualidade, tecnologia e know-how.

\section{CONSIDERACGÖES FINAIS SOBRE A PIRTINÂNCIA

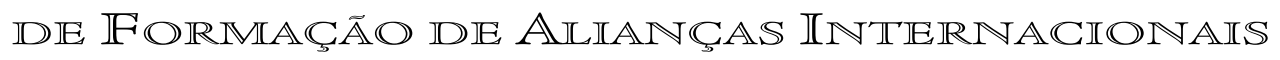 PELA DIVISÃO DE IMIPLEMENTOS A GIICOLAS DA $\mathbb{E}_{\mathbb{M} I P \mathbb{R}} \mathbb{R} \mathbb{N} \mathbb{E} \mathbb{E} A S A \mathbb{D}$ PASSO FUNDO}

Conforme já foi evidenciado ao longo da revisão teórica deste artigo, existe uma ampla variedade de explicações para formação de alianças internacionais por parte de uma empresa. Os benefícios para formação também são diversos e envolvem aspectos tangíveis e intangíveis.

No estudo realizado, observou-se uma convergência de fatores ambientais e organizacionais que indicam uma tendência favorável para formação de alianças internacionais. Com relação ao setor, foi identificado um conjunto de elementos que limita a capacidade de expansão para as empresas brasileiras e que pode ser superado através de alianças com empresas internacionais. Dentre esses fatores, identificou-se carência de tecnologia, para tornar os produtos mais competitivos internacionalmente, e baixo conhecimento das práticas de gestão internacional, utilizando-se basicamente de estratégias de exportação direta para acessar esses mercados.

Em um nível mais macro, também aparece o chamado custo Brasil, com taxas elevadas de juros que dificultam o financiamento de projetos de expansão. No que concerne ao aspecto mais regional, pesquisas indicam um sistema de logística deficiente, o qual eleva o custo de movimentação dos produtos e insumos.

No aspecto gerencial, constatou-se um baixo nível de interação e cooperação entre as empresas na cadeia produtiva e um baixo nível de informações sistematizadas sobre o mercado interno e externo. Associados a esses fatores estão uma consciência empreendedora baixa, quanto à articulação das empresas do setor para obtenção de tecnologia; mão-de-obra com baixo nível de qualificação; e estruturas gerenciais predominantemente familiares - baixo nível de profissionalização. Essas estruturas familiares têm sido marcadas pela resistência à incorporação de inovações tecnológicas e gerenciais e restrição à formação de associações com parceiros internacionais. Cabe destacar, no entanto, uma tendência de contratação de executivos profissionais em maior número pelas empresas familiares de maior porte.

Esses problemas encontrados no setor poderiam reduzir a atratividade das empresas locais para formação de parcerias com empresas estrangeiras. No entanto, pode-se verificar um conjunto de fatores que indicam oportunidades de crescimento do setor, despertando o interesse de investidores internacionais. Entre os fatores que podem atrair os investidores externos estão: a) o baixo nível de internacionalização da concorrência no mercado interno, o qual é ocupado quase $100 \%$ por empresas nacionais; b) setor apresenta um bom nível de estruturação da atividade de produção, quando comparado com os países vizinhos, podendo tornar-se uma base de produção e assistência técnica para os parceiros estrangeiros; c) e finalmente, estudos mostram uma tendência de crescimento da área de plantio no Brasil de 40 milhões de hc. para 90 milhões de hc., o que representa uma significativa expansão do mercado interno.

Pode-se considerar, também, que a estratégia de entrar no mercado através de investimento direto sem parceria seria dificultado pelas especificidades do ambiente institucional brasileiro e pela necessidade de estudos específicos para adaptação das máquinas e implementos agrícolas para o nosso solo. Vale lembrar 
que as empresas brasileiras já acumularam muitos anos de pesquisa para desenvolvimento de produtos adequados às condições de solo local.

Finalmente, é apresentado um conjunto de fatores ambientais e organizacionais que indicam um momento favorável a formação de alianças internacionais nesse setor no Brasil:

\section{Quadro 2 - Condições Ambientais e Organizacionais} Favoráveis à Formação de Parcerias Internacionais

\begin{tabular}{|l|}
\hline Necessidade de tecnologia para internacionalização do setor \\
\hline $\begin{array}{l}\text { Necessidade de know-how gerencial em todas as áreas; principalmente quando } \\
\text { se considera o objetivo de entrada nos mercados de países desenvolvidos. }\end{array}$ \\
\hline $\begin{array}{l}\text { Estagnação do mercado da Europa ocidental, fazendo do mercado brasileiro de } \\
\text { máquinas e implementos agrícola alvo para investida de empresas européias e } \\
\text { americanas. }\end{array}$ \\
\hline $\begin{array}{l}\text { Custo elevado das máquinas importadas para os produtores de países em } \\
\text { desenvolvimento, exigindo preços baseados nos custos locais de produção. }\end{array}$ \\
\hline $\begin{array}{l}\text { Complexidade do mercado e do contexto institucional local, tornando atraente } \\
\text { para os investidores internacionais as estratégias de cooperação com empresas } \\
\text { locais para ingresso mais rápido e mais seguro no mercado }\end{array}$ \\
\hline $\begin{array}{l}\text { Existência de negociações para formação de parcerias e a percepção dos } \\
\text { empresários locais de que estratégias cooperativas representam alternativas } \\
\text { válidas para fazer frente à competição internacional. }\end{array}$
\end{tabular}

No que concerne especificamente à empresa Metasa, a mesma pode obter de parceiros internacionais tecnologias de gestão para se estabelecer no mercado europeu, asiático e americano, bem como compartilhar riscos de novos investimentos. A internacionalização da empresa ficaria facilitada através de uma parceria com uma empresa que já disponha de legitimidade no mercado internacional e que possa oportunizar para a Metasa novos canais de distribuição.

Em síntese, a Metasa poderia, através de uma aliança, reduzir suas dependências ambientais, uma vez que a tendência é o acirramento da competição e o aumento do poder de barganha dos clientes (Pfeffer \& Salancik, 1978; Pfeffer \& Nowak, 1976), bem como poderia desfrutar do prestígio de um parceiro internacional para posicionar-se no mercado de países desenvolvidos, nos quais ainda não dispõe da reputação necessária (Gulati, 1998; DiMaggio \& Powell, 1991). Essa empresa pode oferecer em troca o conhecimento do ambiente institucional brasileiro, uma boa base de produção, controle de canais de distribuição no Brasil e em outros países da América Latina e conhecimentos técnicos sobre as especificidades tecnológicas necessárias para as condições locais. É uma empresa que tem prestígio no âmbito nacional, podendo oferecer maior legitimidade ao parceiro que pretende ingressar no mercado local.

A pertinência da formação de parcerias no setor de máquinas e implementos agrícolas na região de Passo Fundo por empresas locais pode ser explicada considerando a redução de custos de transação, a redução de interdependências ambientais e a obtenção de legitimidade para ingresso em mercados distantes e desconhecidos. As empresas locais, e em especial a Metasa, dispõem de recursos importantes como: controle de parte significativa do mercado doméstico e acesso a uma parte do mercado internacional de países em desenvolvimento; tecnologia de produto para condições de produção na América Latina; controle dos canais internos de distribuição e comercialização; conhecimento do contexto institucional; pessoal técnico qualificado para a área de produção; e, finalmente, infraestrutura de máquinas para produção. Esse é um setor importante para o país, o que pode ser traduzido em possibilidades de incentivo ao longo da cadeia produtiva, bem como é um dos setores em crescimento ao longo de toda a cadeia. 


\section{$\mathbb{R} \mathbb{E} \mathbb{E} \mathbb{R} \hat{\mathbb{E}} \mathbb{N} C \mathbb{I} \mathbb{S}$}

ABIMAQ. Associação Brasileira da Indústria de Máquinas. Disponível em <http:// www.abimaq.org.br >. Acesso em: 17 set.2003

ALTER, C.; HAGE, J. Organizations working together. Newbury Park, California: Sage Publications, 1993.

BALESTRO, M.V.; JÚNIOR, J.A.V.A; LOPES, M.C.; PELLEGRIN, I. de. A experiência da Rede PETRO-RS: uma estratégia para o desenvolvimento das capacidades dinâmicas. RAC - Revista de Administração Contemporânea. Curitiba/PR, Ed. Especial, V.8, 2004.

BALDI, M.; LOPES, F. D. Rede - forma híbrida ou nova forma? Revista Portuguesa e Brasileira de Gestão. Portugal/Brasil. V.1, n.0 3, p.32-46, 2002.

BELL, D. O advento da sociedade pós-industrial. São Paulo: CULTRIX, 1973.

BLEEK, J., ERNST, D. The death of the predator. In: BLEEK, Joel, ERNST, D.

Collaborating to Compete: Using Strategic Alliances and Acquisitions in the Global Marketplace. New York: Wiley, 1993.

BORYS, B; JEMINSON, D. B. Hybrid arrangements as strategic alliances: theoretical issues in organizational combinations. Academy of Management Review. New York, n.14, p. 234-49, 1989.

BURREL, G.; MORGAN, G. Sociological paradigms and organizational analysis. London: Heinemann, 1979.

CORREA, Marcio Rogério. Diagnóstico do arranjo produtivo local: caracterização do arranjo produtivo do setorial metal-mecânico da região da produção do RS. Sebrae: 2003

CLEGG, Stewart R. Frameworks of power. London: Sage, 1990.

CONTRACTOR, F.; LORANGE, P. Why should firms cooperate? The strategy and economics basis for cooperative ventures. In: CONTRACTOR, F.; LORANGE, $P$ (eds.). Cooperative Strategies in International Business. Lexington, MA: Lexington Books, 1988. p. 03-28.

CYRINO, A. B.; JÚNIOR, M. de M. Emerging global players: evidences from the internationalization processes of Brazilian firms. In: ENCONTRO NACIONAL DOS PROGRAMAS DE PÓS-GRADUAÇÃO EM ADMINISTRAÇÃO, 27, 2003, Atibaia/SP. ANAIS DO XXVII ENANPAD, Curitiba, ANPAD, 2003. 1 CD-ROM.

DIMAGGIO, P. J.; POWELL, W. W. The iron cage revisited: institutional isomorphism and collective rationality in organizational fields. American Sociological Review. Ann Arbor, MI, v. 48, p. 147-160, 1983.

GRANOVETTER, M. Economic action and social structure: the problem of embededdness. American Journal of Sociology. Chicago, Illinois, v. 91, p. 481$510,1985$.

GULATI, R. Alliances and networks. Strategic Management Journal. Hoboken, NJ, v. 19, p. 293-317, 1998.

HAUNSCHILD, P. R. Inter-organizational imitation: the impact of interlocks on corporate acquisition activity. Administrative Science Quarterly. Ann Arbor, n. 38, p. 564-92, 1993.

HEXSEL, C. A.. GÁRATE, H. E.. Comércio do século XX de Passo Fundo. Gráfica e Editora Berthier:2002.p.153-154

HATCH, Mary Jo. Organization theory. Oxford, Oxford University Press, 1997. 
LANIADO, R.; BAIARDI, A.. A contribuição das redes na formação da cooperação empresarial: um estudo de caso. Organização \& Sociedade. Salvador/BA, V.10, No 27, 2003.

LARSON, A. Network dyads in entrepreneurial settings: a study of the governance of exchange relationships. Administrative Science Quarterly. Ann Arbor, v. 37, p. 76-104, 1992.

LOPES, Fernando Dias. A influência do ambiente institucional na formação de joint ventures internacionais: um estudo de caso na Puig-Memphis. Tese (Doutorado em Administração). Programa de Pós-Graduação em Administração, Escola de Administração, Universidade Federal do Rio Grande do Sul, Porto Alegre, .2003.

METASA. Disponível em:<http://www.metasa.com.br>. Acesso em: 4 set. 2003

MINTZBERG, H. et alli. Safári de estratégia. Porto Alegre: Bookman, 2000.

MORGAN, Gareth. Imagens da organização. São Paulo: Atlas, 1996.

OLIVEIRA, Virgínia I.; DRUMMOND, Aldemir; RODRIGUES, Suzana B. Joint venture: aprendizagem tecnológica e gerencial. In: RODRIGUES, Suzana B. (org.).

Competitividade, alianças estratégicas e gerência internacional. São Paulo: Atlas, 1999. p. 99-121.

PFEFFER, J., NOWAK, P. Joint ventures and inter-organizational interdependence. Administrative Science Quarterly. Ann Arbor, v. 21, p. 398-418, 1976.

; SALANCIK, G. The external control of organizations: a resource dependence perspective. New York: Harper and Row, 1978.

POWELL, W. W.; DIMAGGIO, P. J. The new institutionalism in organizational analysis. Chicago, The University of Chicago Press. 1991.

POWELL, W. W. Learning from collaboration: knowledge and networks and pharmaceutical industries. California Management Review. Berkeley, CA, v. 40, n. 3, p. 228-240, 1998.

Neither market nor hierarchy: network forms of organization. In:

STAW, B. M.; CUMMINGS, L. L. (eds.). Research in Organizational Behavior: Greenwich, CT: JAI Press, 1990. p. 295-336.

Hybrid organizational arrangements: new form or transitional

development? California Management Review. Berkeley, CA, v. 30 (1), p. 67-87, 1987.

RODRIGUES, Suzana B. Formação de alianças estratégicas em países emergentes: o caso Brasil-China. In: RODRIGUES, Suzana B. (org.). Competitividade, alianças estratégicas e gerência internacional. São Paulo: Atlas. 1999. p. 183-205.

ROBERTS, Peter W.; GREENWOOD, Royston. Integrating transaction cost and institutional theories: toward a constrained-efficiency framework for understanding organizational design adoption. The Academy of Management Review. New York, v. 22, p. 346-373, April. 1997.

THORELLI, H. B. Networks: between markets and hierarchies. Strategic Management Journal. Hoboken, NJ, v. 7, p. 37-51, 1986.

WILLIAMSON, O. The economic institution of capitalism. New York: Free Press, 1985

Transaction-cost economics: the governance of contractual relations. In: WILLIAMSON, O. Industrial Organization. Cheltenham, UK; Brookfield, Vt.; USA: Elgar Pub., 1996. 